\title{
Erratum to: Identification of Bacteria by Surface-Enhanced Raman Spectra after Peroxide Treatment ${ }^{1}$
}

\author{
D. S. Kopitsyn ${ }^{a}$, M. V. Gorbachevskii ${ }^{a}$, E. A. Botchkova ${ }^{a}$, M. A. Bychenko ${ }^{a}$, and A. A. Novikov ${ }^{a}$ * \\ ${ }^{a}$ Gubkin University, Moscow, 119991 Russia \\ *e-mail: novikov.a@gubkin.ru \\ Submitted April 23, 2019; accepted for publication April 23, 2019
}

DOI: $10.1134 / \mathrm{S} 0003683819120019$

Page 81, right column, line 6 from bottom, the sentence should read:

This work was supported by the Russian Science Foundation (Project no. 17-79-10489).

The original article can be found online at

https://doi.org/10.1134/S0003683819010095.

\footnotetext{
${ }^{1}$ The article was translated by the authors.
} 